\title{
Binding Sites in the Rat Brain for Escherichia coli S Fimbriae Associated with Neonatal Meningitis
}

\author{
Jaakko Parkkinen, "* Timo K. Korhonen,' Auli Pere," Jörg Hacker," and Seppo Soinila*1 \\ Departments of Medical Chemistry, ${ }^{*}$ General Microbiology, and Anatomy, and Neurobiological Research Unit, ${ }^{\star}$ \\ University of Helsinki, 00170 Helsinki, Finland; Institute for Genetics and Microbiology, \\ University of Würzburg, 8700 Würzburg, Federal Republic of Germany"
}

\begin{abstract}
Escherichia coli strains that cause sepsis and meningitis in neonatal infants carry $\mathbf{S}$ fimbriae that bind to sialyl galactoside units of cell surface glycoproteins. To investigate the possible role of $\mathrm{S}$ fimbriae in determining the tissue tropism of neonatal meningitis, we have studied the presence of binding sites for $S$ fimbriae in different tissues of the neonatal rat which is susceptible to meningitis caused by S-fimbriated $E$. coli. Purified $S$ fimbriae were incubated on cryostat sections of different rat organs and their binding was assessed by indirect immunofluorescence. In the brain of the neonatal rat, $S$ fimbriae specifically bound to the luminal surfaces of the vascular endothelium and of the epithelium lining the choroid plexuses and brain ventricles. The binding was completely inhibited by the trisaccharide NeuAc $\alpha 2-3 \mathrm{Gal} \beta 1-4 \mathrm{Glc}$, a receptor analogue of $\mathrm{S}$ fimbriae, and by a preceding neuraminidase treatment of the sections. A recombinant $E$. coli strain expressing $S$ fimbriae adhered in large numbers to the same tissue sites in the neonatal brain sections as did the purified fimbriae, whereas the nonfimbriated host strain and a recombinant strain expressing $\mathbf{P}$ fimbriae did not adhere to brain tissues. The results suggest that adhesion of S-fimbriated bacteria to the binding sites observed in the neonatal brain has a pathogenetic role during bacterial invasion from circulation into the cerebrospinal fluid.
\end{abstract}

\section{Introduction}

Bacterial meningitis is generally regarded as a hematogeneous infection, but the bacterial and host factors that result in the meningeal localization of the blood-born bacteria have been unknown (1-3). The invasion of bacteria from circulation into the cerebrospinal fluid (CSF) ${ }^{1}$ may involve specific mechanisms since it frequently occurs with certain encapsulated organisms, e.g., Haemophilus influenzae and Neisseria meningitidis, but very infrequently with other organisms that cause bacteremia, e.g., Streptococcus viridans (3). This has been pro-

Address all correspondence to Dr. J. Parkkinen, Department of Medical Chemistry, University of Helsinki, Siltavuorenpenger 10, SF-00170 Helsinki, Finland.

Received for publication 20 February 1987 and in revised form 24 September 1987.

1. Abbreviation used in this paper: CSF, cerebrospinal fluid.

J. Clin. Invest.

(c) The American Society for Clinical Investigation, Inc.

$0021-9738 / 88 / 03 / 0860 / 06 \$ 2.00$

Volume 81, March 1988, 860-865 posed to depend on the presence of specific receptors for the bacteria on the blood vessels that supply the central nervous system (3), but to date, there has been no evidence for the existence of such receptors.

Escherichia coli is a major cause of meningitis in neonatal infants but is rarely encountered in similar infections in older children (4). We have found a novel cell binding activity in $E$. coli that is specific for the terminal NeuAc $\alpha 2-3 \mathrm{Gal}$ disaccharide units of cell surface glycoproteins $(5,6)$. This adhesion activity is mediated by bacterial $\mathrm{S}$ fimbriae (7) which are associated with $E$. coli strains isolated from blood and CSF of septic infants (8). S fimbriae typically occur in combination with the serotype $018 \mathrm{ac}: \mathrm{K} 1: \mathrm{H} 7$ which predominates among the strains isolated from septic neonatal infections (8). Strains of this serotype cause experimental meningitis in neonatal rats (9), and it has been shown that the expression of S fimbriae is induced during a systemic infection in mice (10). Since these findings suggest that $\mathrm{S}$ fimbriae increase the virulence of $E$. coli during the invasive stage of infection, we have investigated the presence of receptors for $\mathrm{S}$ fimbriae in different tissues of the neonatal rat. We show here that such receptors are present in the brain on the vascular endothelium and on the epithelial lining of the choroid plexus and brain ventricles. The possible pathogenetic role of these receptors during the CSF invasion of S-fimbriated $E$. coli is discussed.

\section{Methods}

Animals. Sprague-Dawley rats aged 3-30 d were used.

Bacteria. The nonfimbriated $E$. coli strain $\mathrm{HB} 101$ was cultured on Luria agar. The strain HB101(pANN801-4) that carries the recombinant plasmid encoding $S$ fimbriae $(11,12)$, and the recombinant strain EH824 that carries the genes encoding P fimbriae (13) were cultivated on Luria agar supplemented with tetracycline $(15 \mu \mathrm{g} / \mathrm{ml})$ or ampicillin $(100 \mu \mathrm{g} / \mathrm{ml})$, respectively. The recombinant strain HB101(pANN80113/Tn5-32) which produces $S$ fimbriae that lack the binding ability (11) was cultivated on Luria agar supplemented with kanamycin (50 $\mu \mathrm{g} / \mathrm{ml})$ and ampicillin $(100 \mu \mathrm{g} / \mathrm{ml})$. Bacteria were labeled with FITC (Sigma Chemical Co., St. Louis, MO) by incubating $4 \times 10^{10}$ bacteria in $1 \mathrm{ml}$ of $20 \mathrm{mM}$ sodium borate buffer, $\mathrm{pH} 9.0$, containing $150 \mathrm{mM}$ $\mathrm{NaCl}$ and $75 \mu \mathrm{l} / \mathrm{ml}$ FITC for $30 \mathrm{~min}$ at $23^{\circ} \mathrm{C}$. The reaction mixture was layered on top of $4 \mathrm{ml}$ of PBS (10 mM sodium phosphate, $150 \mathrm{mM}$ $\mathrm{NaCl}, \mathrm{pH}$ 7.4) containing $6 \%$ (wt/vol) BSA. Bacteria were pelleted by centrifugation ( $15 \mathrm{~min}, 1,500 \mathrm{~g}$ ), and washed once with PBS.

Preparation of cryostat sections. Rats were anesthetized with sodium pentobarbital and fixed by transcardial perfusion with $4 \%(\mathrm{wt} /$ vol) paraformaldehyde in PBS for 10 min after an initial flush with PBS. Brain, kidney, liver, lung, and spleen were dissected out, immersed in the same fixative at $23^{\circ} \mathrm{C}$ for $2 \mathrm{~h}$, and then incubated in PBS containing $20 \%\left(\mathrm{wt} / \mathrm{vol}\right.$ ) sucrose at $4^{\circ} \mathrm{C}$ for $1-3 \mathrm{~d}$. The specimens were frozen with carbon dioxide ice, and $10 \mu \mathrm{m}$ cryostat sections were cut. 
The sections were allowed to dry on chrome-aluna-gelatine coated glass slides for $10 \mathrm{~min}$ at $23^{\circ} \mathrm{C}$, and the slides were washed with PBS for $15 \mathrm{~min}$. Neuraminidase treatment of the sections was carried out with Vibrio cholerae neuraminidase (Calbiochem Behring Diagnostics, La Jolla, CA), $0.1 \mathrm{U} / \mathrm{ml}$ in PBS containing $2 \mathrm{mM} \mathrm{CaCl}_{2}$ at $37^{\circ} \mathrm{C}$ for $1 \mathrm{~h}$, followed by three washings in PBS, 5 min each.

Binding of purified $S$ fimbriae to cryostat sections. S fimbriae were tested for binding to the tissue sections essentially as described before (12). The fimbriae of the recombinant strain HB101(pANN801-4) were purified and antiserum against them was raised in rabbits as described before (7). $1 \mathrm{ml}$ of the antiserum was adsorbed at $4^{\circ} \mathrm{C}$ for 16 $\mathrm{h}$ with $4 \mathrm{ml}$ of $10 \%$ (wt/vol) neonatal rat brain tissue homogenized in PBS containing $2 \mathrm{mM}$ PMSF and $1 \%$ (vol/vol) aprotinin solution (Sigma Chemical Co.), and then the adsorbed serum was centrifuged $(30 \mathrm{~min}, 100,000 \mathrm{~g})$. The purified fimbriae were incubated on the sections at a concentration of $1 \mathrm{mg} / \mathrm{ml}$ in PBS at $4^{\circ} \mathrm{C}$ for $16 \mathrm{~h}$. The controls were incubated in the presence of $20 \mathrm{mM}$ NeuAc $\alpha 2-3 \mathrm{Gal} \beta 1$ 4Glc. This trisaccharide was isolated from bovine colostrum (14), dissolved in PBS, and adjusted to $\mathrm{pH} 7.4$ with $\mathrm{NaOH}$. The slides were washed three times with cold PBS, 5 min each, and incubated in 4\% paraformaldehyde in PBS for 15 min. After washing three times in PBS, 5 min each, the sections were incubated with adsorbed anti-Sfimbria serum diluted $1: 100$ in PBS at $23^{\circ} \mathrm{C}$ for $1 \mathrm{~h}$, washed three times with PBS, and incubated for $1 \mathrm{~h}$ with FITC-conjugated swine antirabbit Igs (Dako Corp., Copenhagen, Denmark) diluted 1:40 in PBS. The slides were washed three times with PBS, mounted with glyserol, and examined with a Leitz Dialux 20 fluorescence microscope. The photographs were taken on Kodak Tri-X film using an Vario-Orthomat microscope camera.

Bacterial adhesion to cryostat sections. FITC-labeled bacteria were incubated on the sections at a density of $2 \times 10^{9}$ bacteria per $\mathrm{ml}$ in PBS at $4^{\circ} \mathrm{C}$ for $60 \mathrm{~min}$, the slides were washed three times with cold PBS with slight agitation, $5 \mathrm{~min}$ each, and mounted for microscopy as described above.

\section{Results}

Incubation of purified S fimbriae on cryostat sections of neonatal rat brain revealed intense binding to the epithelial lining of the choroid plexuses and brain ventricles (Fig. $1 A$ ). Vascular endothelium was also stained with $\mathrm{S}$ fimbriae (Fig. 1 D) whereas other tissues in the brain did not significantly bind $S$ fimbriae. The binding was completely inhibited in the presence of $20 \mathrm{mM}$ NeuAc $\alpha 2-3 \mathrm{Gal} \beta 1-4 \mathrm{Glc}$, a receptor analogue of $S$ fimbriae (6), indicating that the observed binding was specific (Fig. $1 B$ ). Neuraminidase treatment of the tissue sections before overlay with $\mathrm{S}$ fimbriae also abolished binding, which supports the assumption that the receptors were sialic acidcontaining structures (not shown).

Most of the receptors in the choroid plexus were located on the luminal surface of the epithelial cells but some S-fimbriabinding structures in the core of the plexus were also visualized (Fig. $1 C$ ). At least some of these structures probably corresponded to capillary endothelial cells since adjacent sections stained with hematoxylin-eosin revealed the presence of epithelial cells in similar locations (not shown). The receptors on the ventricular epithelial or ependyma cells were also located on the luminal surface (Fig. $1 A$ ). In the cerebral cortex, $\mathrm{S}$ fimbriae decorated the lumen of small pores (Fig. $1 D$ ) which corresponded to the arterioles or venules that were visualized by hematoxylin-eosin staining of adjacent sections. Large blood vessels in the subarachnoid space were occasionally preserved in the brain sections and their luminal surface was also specifically stained by $\mathrm{S}$ fimbriae (Fig. $1 \mathrm{D}$ ). Some other, poorly defined structures in the subarachnoid space gave variable reactions in the staining and were presumed to correspond to pieces of endothelium broken during tissue preparation.

When brain sections of rats between 3 and $30 \mathrm{~d}$ old were compared for binding of $\mathrm{S}$ fimbriae, the same tissue sites were found positive in all sections. However, the choroid plexuses and ventricular epithelium of rats older than 2 wk were less uniformly stained than those of the neonatal animals (not shown). Investigation of other organs of the neonatal rat revealed that $\mathrm{S}$ fimbriae bind to the glomeruli and vascular endothelium in kidney and, more weakly, to vascular endothelium and alveolar epithelium in lung. No binding was observed in liver and spleen (not shown).

The adhesion of S-fimbriated bacteria to the cryostat sections was studied with the FITC-conjugated strain HB101(pANN801-4) that carries the recombinant plasmid encoding $S$ fimbriae $(11,12)$. The bacterium adhered in large numbers to the same tissue sites in the brain of the neonatal rat as did the purified fimbriae, i.e., to the epithelial lining of the choroid plexus and ventricles, and to the vascular endothelium (Fig. 2, $A$ and $C$ ). Bacterial adhesion was inhibited by $\sim 70 \%$ in the presence of $20 \mathrm{mM} \mathrm{NeuAc} \alpha 2-3 \mathrm{Gal} \beta 1-4 \mathrm{Glc}$ (Figs. 2, $B$ and $D$ ). The recombinant strain HB101(pANN801-13/Tn532) that produces $S$ fimbriae lacking the binding capacity (11) did not adhere to brain tissues, nor did the nonfimbriated host strain HB101 (Fig. $3 C$ ). This confirmed that the adhesion was a specific property conferred by $\mathrm{S}$ fimbriae and not a nonspecific interaction between $E$. coli and the brain tissues. For comparison, the P-fimbriated strain EH824 (13) was studied for binding to brain tissues as a representative of fimbriae associated with human infections other than meningitis. No binding of this bacterium to brain tissues was observed (Fig. $3 \mathrm{~B}$ ).

To further study the possible age-dependent difference in the density of bacterial binding sites suggested by binding of purified S fimbriae, brain sections from 3- and 30-d-old rats were compared for binding of S-fimbriated bacteria. About two times more bacteria adhered under identical experimental conditions to the choroid plexuses of the neonatal rats than to those of the adult animals (Fig. 4).

\section{Discussion}

The present study demonstrates the presence of specific binding sites for $S$ fimbriae on three different cell types of the neonatal rat brain: the vascular endothelial cells, the epithelial cells of the choroid plexus, and the ependyma cells lining the brain ventricles. This was indicated by the following lines of evidence: firstly, purified $\mathrm{S}$ fimbriae bound to these tissue sites. Secondly, the binding was totally inhibited by the trisaccharide receptor analogue of S fimbriae. Thirdly, preceding neuraminidase treatment of the sections abolished binding of S fimbriae. Fourthly, the S-fimbriated $E$. coli strain adhered to the same tissue sites as the purified fimbriae, and fifthly, the nonfimbriated host strain and a recombinant strain expressing $P$ fimbriae did not adhere to brain tissues. The binding sites were localized to the luminal surface of the endothelial and epithelial cells and should therefore be accessible for bacteria present in blood or CSF. These results thus provide a molecular basis for the capacity of S-fimbriated $E$. coli to cause meningitis. 

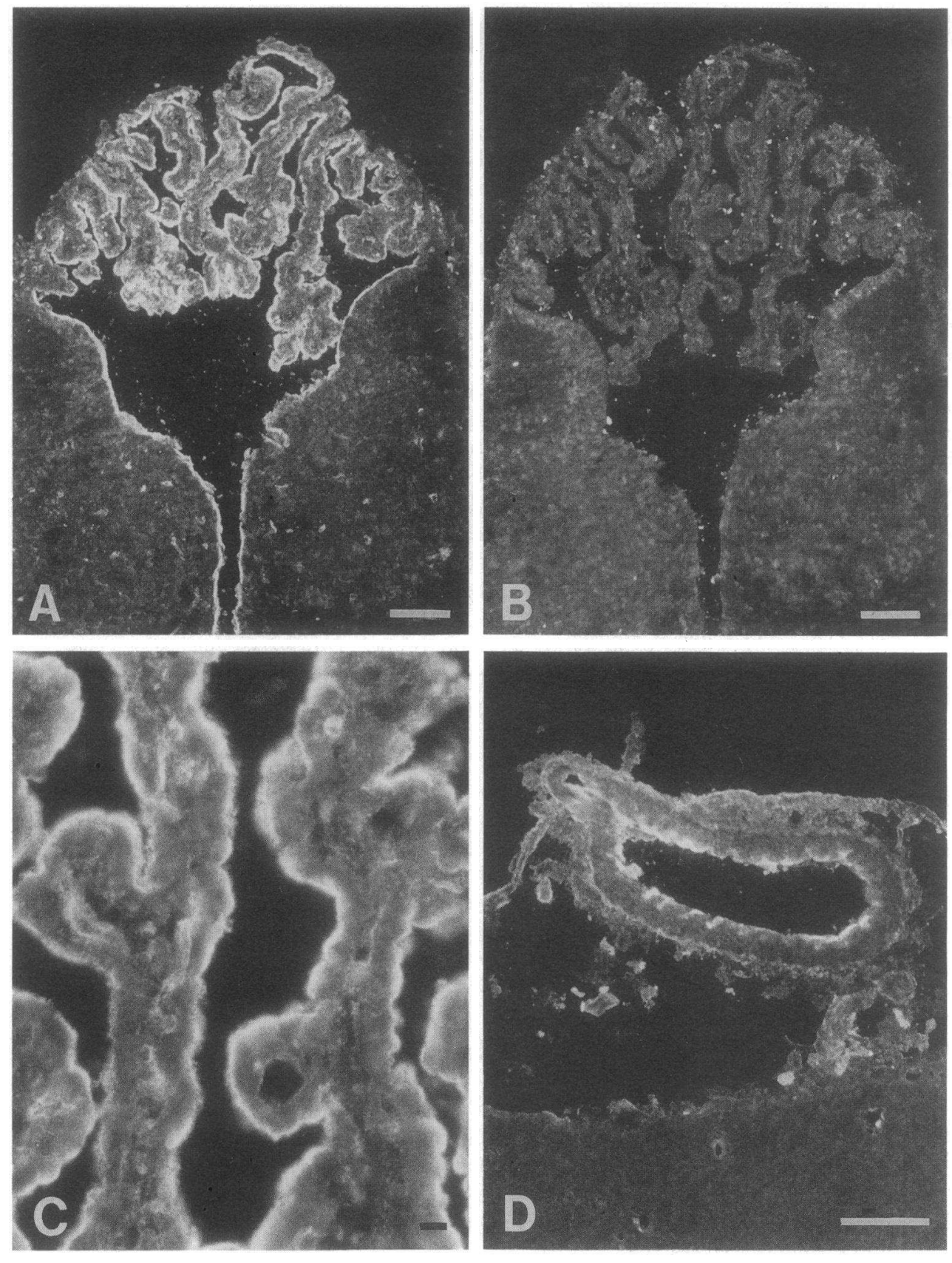

Figure 1. Binding of purified S fimbriae to brain sections of a 3-d-old rat. The fimbriae bound to the luminal surface of the epithelial cells lining the choroid plexuses and ventricles $(A, C)$, and the binding was completely inhibited in the presence of $20 \mathrm{mM}$ NeuAc $\alpha 2-3 \mathrm{Gal} \beta 1-4 \mathrm{Glc}$ $(B)$. (D) Binding of S fimbriae to the endothelium of a subarachnoid blood vessel (top) and of small cortical blood vessels (bottom); perivascular autofluorescence seen in the large vessel. Scale bar indicates 100 $\mu \mathrm{m}(A, B, D)$ or $10 \mu \mathrm{m}(C)$.

During invasion from circulation into the CSF, bacteria must first penetrate the vascular endothelium. The exact mechanism of bacterial extravasation is not known but their ability to adhere to the endothelial cells should facilitate this process since it resists clearance by the blood flow and brings the bacteria and the endothelial cell into close contact. The finding that the vascular endothelium in kidney and lung also bound $\mathrm{S}$ fimbriae indicates that the endothelial cell receptors are not restricted to the central nervous system. On the other hand, binding of $S$ fimbriae to vascular endothelium in vivo might be inhibited by the acute phase protein $\alpha_{1}$ acid glycoprotein that in vitro inhibits binding of S-fimbriated bacteria to the receptors on the human erythrocytes (6) and is present in blood in considerable concentrations. The pathophysiological role of the endothelial cell receptors of $S$ fimbriae remains thus to be resolved.
Studies on the pathogenesis of $H$. influenzae meningitis in the neonatal rat have indicated that the first site of inflammation in the cranial vault is the choroid plexus, and that bacterial densities early in disease are higher in the lateral ventricles than in the cisterna magna or in the subarachnoid space (2). These results suggested that bacteria enter the CSF compartment via the choroid plexus, which is also supported by the exceptionally high blood flow in this organ and by the lack of intercellular tight junctions in its thin, fenestrated endothelium (15). Also, meningococcal meningitis is widely believed to start in the choroid plexus and a similar pathogenetic sequence has been suggested for tuberculous meningitis (16). In this respect, the strong binding of $S$ fimbriae to the epithelial lining of the choroid plexus (Figs. 1 and 2) is of special interest. On the other hand, bacteria have been shown to exit from the CSF to the venous blood through the arachnoid villi (17). The 

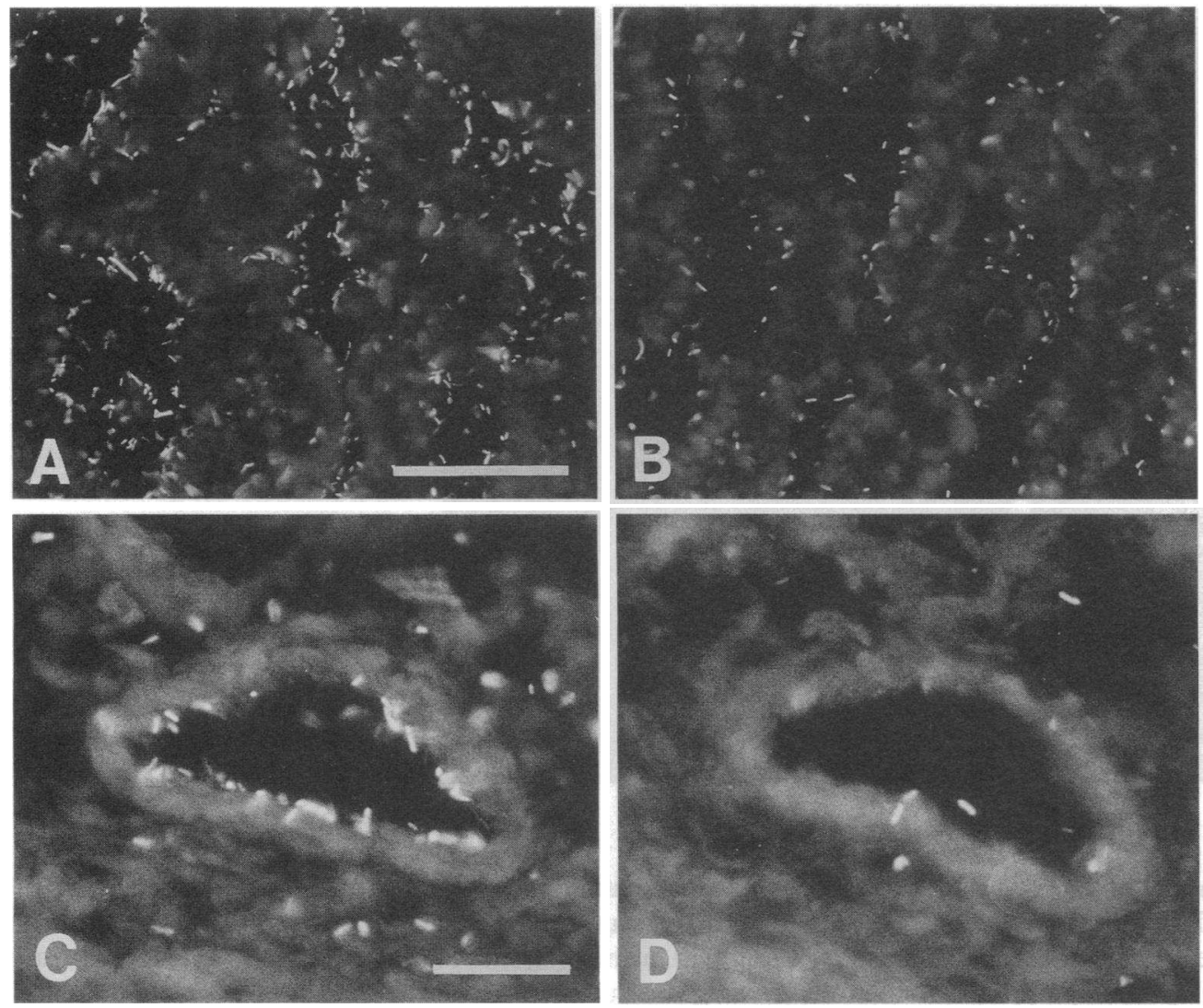

Figure 2. Binding of the Sfimbriated $E$. coli strain HB101 (pANN801-4) to brain sections of a 3-d-old rat. FITClabeled bacteria adhered to the choroid plexus $(A)$ and to the endothelium of a subarachnoid blood vessel $(C)$. $(B, D)$ Binding of bacteria to the corresponding structures in the presence of NeuAc $\alpha 2-3 G a 1 \beta 1-4 G l c$. Scale bar indicates $100 \mu \mathrm{m}(A, B)$ or $40 \mu \mathrm{m}(C, D)$.
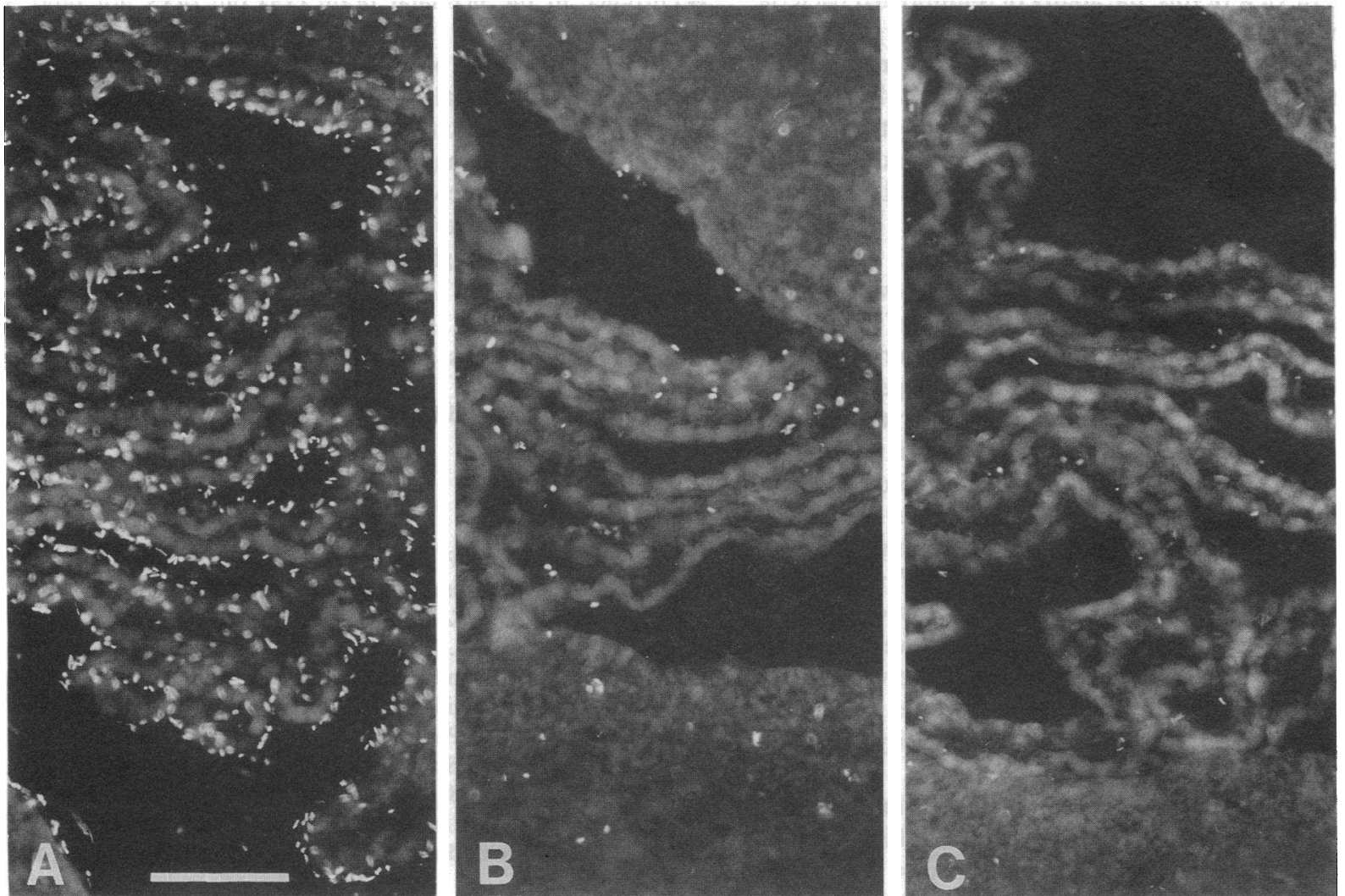

Figure 3. Adhesion of $E$. coli strains expressing different types of fimbriae to neonatal rat brain. The S-fimbriated strain HB101(pANN801-4) $(A)$, the P-fimbriated strain EH824 $(B)$, and the nonfimbriated host strain HB101 $(C)$ were incubated on brain sections from a 4-d-old rat. Scale bar indicates $100 \mu \mathrm{m}$. 

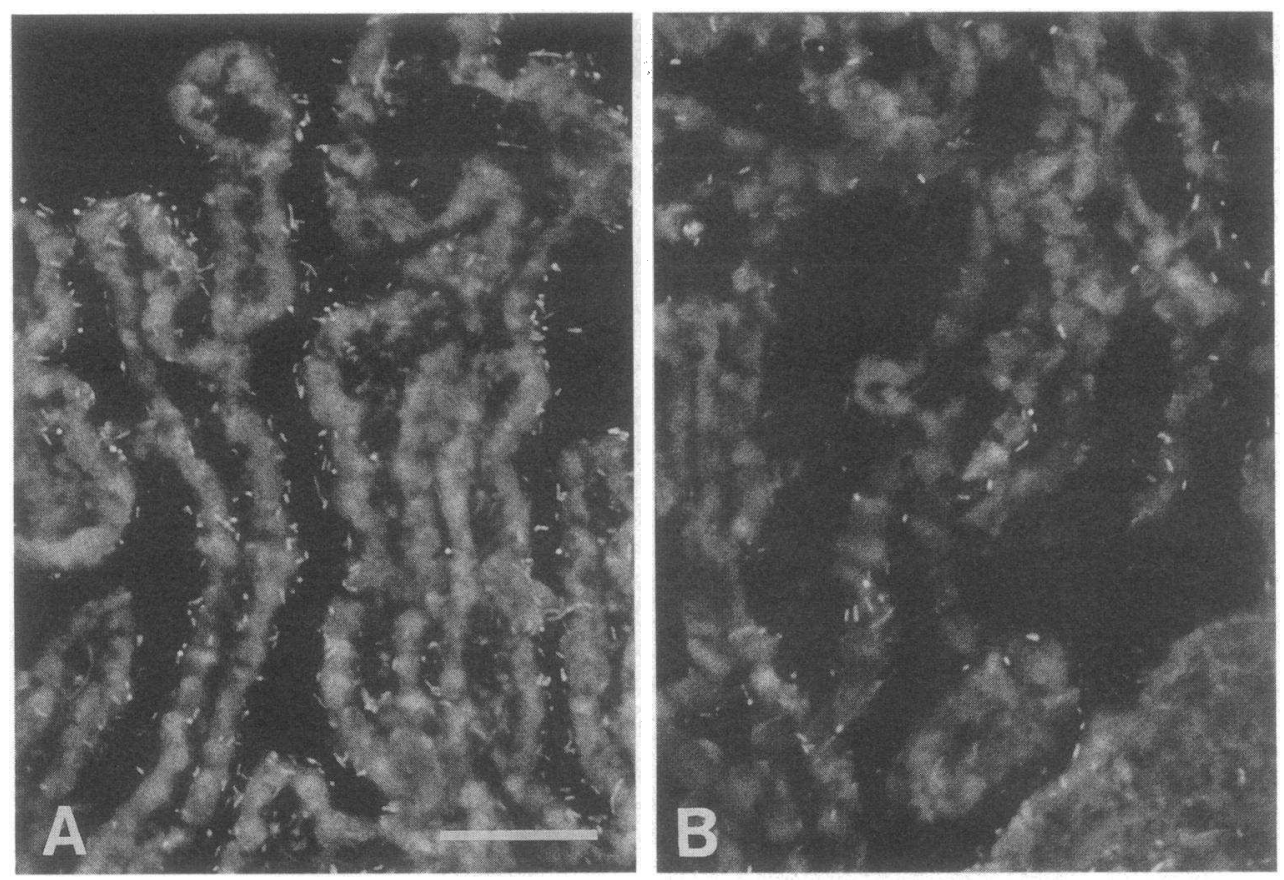

Figure 4. Binding of the Sfimbriated $E$. coli strain HB101(pANN801-4) to choroid plexuses of a neonatal and adult rat. FITC-labeled bacteria were incubated on the brain sections from a 3-d-old $(A)$ and a 30-d-old rat $(B)$. Scale bar indicates $100 \mu \mathrm{m}$.

infection of the CSF compartment thus appears as a kinetic process with bacteria entering from blood and being cleared into the cerebral venous sinuses within the CSF flow. The balance of bacterial ingress and egress is proposed to be important in determining the acquisition of meningitis and its severity (2). In view of this, the ability of S-fimbriated bacteria to recognize binding sites on the epithelial lining of choroid plexuses and ventricles obviously provides the means by which the bacteria are able to resist mechanical clearance by the CSF flow. Adhesion of bacteria to these tissue sites may thus be one of the so far unknown factors that decrease their exit from the CSF so that bacterial densities equivalent to clinical meningitis are reached.

Interestingly, the binding of S-fimbriated $E$. coli to the plexal and ventricular epithelium was clearly lower on the brain sections of the 30-d-old rats than on those of the 3-d-old animals (Fig. 4). This suggests that the density or affinity of bacterial receptors is decreased after the neonatal period which parallels the decrease in the susceptibility of the rat for $E$. coli meningitis. In the rat meningitis model, meningitis was readily produced in 5-d-old animals whereas animals 15 or $30 \mathrm{~d}$ old never developed meningitis (18). This suggests that age-dependent expression of binding sites within the brain might contribute to the age-specific predisposition to $E$. coli meningitis. However, 30-d-old rats were found to be almost completely resistant also to bacteremia which precedes the development of meningitis (18). It is therefore likely that the observed age-dependent difference in bacterial receptor densities in choroid plexuses is not a major cause for the age-specificity of $E$. coli meningitis.

In terms of the known binding specificity of S fimbriae, the receptors observed in the rat brain probably are highly sialylated glycoproteins. S fimbriae have been shown to possess binding specificity for the terminal NeuAc $\alpha 2-3 \mathrm{Gal}$ sequence, and on the erythrocyte surface their binding sites were identified as the O-linked NeuAc $\alpha 2-3 \mathrm{Gal} \beta 1-3 \mathrm{GalNAc}$ chains of the sialoglycoprotein glycophorin A (6). The finding of the present study that neuraminidase treatment of the brain sections abolished their capacity to bind S fimbriae supports the assumption that the binding sites in the brain, too, are sialic acid-containing structures. However, it should be emphasized that they are different from polysialic acid that has strict age-dependent occurrence in the neonatal brain (19) but does not bind $S$ fimbriae $(5,7)$.

In conclusion, the presence of specific binding sites for $S$ fimbriae in the neonatal rat brain suggests that bacterial adhesion is one of the unknown factors that determine the tissue tropism of neonatal meningitis caused by $E$. coli. The observations that meningococci in the CSF of patients with acute disease carry fimbriae $(20,21)$ suggest that other bacteria causing meningitis might also recognize binding sites within the brain.

\section{Acknowledgments}

This work was supported by the Sigrid Jusélius Foundation and the Academy of Finland.

\section{References}

1. Moxon, E. R., and P. A. Murphy. 1978. Haemophilus influenzae bacteremia and meningitis resulting from survival of a single organism. Proc. Natl. Acad. Sci. USA. 75:1534-1536.

2. Smith, A. L., R. S. Daum, D. Scheifele, V. Syriopolou, D. R. Averill, M. C. Roberts, and T. L. Stull. 1982. Pathogenesis of Haemophilus influenzae meningitis. In Haemophilus influenzae, Epidemiology, Immunology, and Prevention of Disease. S. H. Sell and P. F. Wright, editors. Elsevier Science Publishing Co., New York. 89-109.

3. McGee, Z. A. 1985. Bacterial meningitis: current status and directions for the future. In Bacterial Meningitis. M. A. Sande, A. L. Smith, and R. K. Root, editors. Churchill Livingstone Inc., New York. 253-264.

4. Broome, C. V., and W. F. Schlech. 1985. Recent developments in the epidemiology of bacterial meningitis. In Bacterial Meningitis. M. A. Sande, A. L. Smith, and R. K. Root, editors. Churchill Livingstone Inc., New York. 1-10. 
5. Parkkinen, J., J. Finne, M. Achtman, V. Väisänen-Rhen, and T. K. Korhonen. 1982. Escherichia coli strains binding neuraminyla2-3 galactosides. Biochem. Biophys. Res. Commun. 111:456461.

6. Parkkinen, J., G. N. Rogers, T. K. Korhonen, W. Dahr, and J. Finne. 1986. Identification of the O-linked sialyloligosaccharides of glycophorin A as the erythrocyte receptors of S-fimbriated Escherichia coli. Infect. Immun. 54:37-42.

7. Korhonen, T. K., V. Väisänen-Rhen, M. Rhen, A. Pere, J. Parkkinen, and J. Finne. 1984. Escherichia coli fimbriae recognizing sialyl galactosides. J. Bacteriol. 159:762-766.

8. Korhonen, T. K., M. V. Valtonen, J. Parkkinen, V. VäisänenRhen, J. Finne, F. Ørskov, I. Ørskov, S. B. Svenson, and P. H. Mäkelä. 1985. Serotypes, hemolysin production, and receptor recognition of Escherichia coli strains associated with neonatal sepsis and meningitis. Infect. Immun. 48:486-491.

9. Bortolussi, R., P. Ferrieri, and L. W. Wannamaker. 1978. Dynamics of Escherichia coli infection and meningitis in infants rats. Infect. Immun. 22:480-485.

10. Nowicki, B., J. Vuopio-Varkila, P. Viljanen, T. K. Korhonen, and P. H. Mäkelä. 1986. Fimbrial phase variation and systemic Escherichia coli infection studied in the mouse peritonitis model. Microb. Pathogen. 1:335-347.

11. Hacker, J., G. Schmidt, C. Hughes, S. Knapp, M. Marget, and W. Goebel. 1985. Cloning and characterization of genes involved in production of mannose-resistant, neuraminidase-susceptible (x) fimbriae from a uropathogenic 06:K15:H31 Escherichia coli strain. Infect. Immun. 47:434-440.

12. Korhonen, T. K., J. Parkkinen, J. Hacker, J. Finne, A. Pere, M.
Rhen, and H. Holthöfer. 1986. Binding of Escherichia coli S fimbriae to human kidney epithelium. Infect. Immun. 54:322-327.

13. Rhen, M., J. Knowles, M. Penttilä, M. Sarvas, and T. K. Korhonen. 1983. Molecular cloning of DNA fragments containing the structural genes of Escherichia coli $\mathrm{P}$ fimbriae. FEMS (Fed. Eur. Microbiol. Soc.) Microbiol. Lett. 19:119-123.

14. Parkkinen, J., and J. Finne. 1987. Isolation of sialyloligosaccharides and sialyloligosaccharide phosphates from bovine colostrum and human urine. Methods Enzymol. 138:289-300.

15. Peters, A., S. L. Palay, and H. Webster. 1976. The Fine Structure of the Nervous System. W. B. Saunders Co., Philadelphia. 406 pp.

16. Levine, S. 1987. Choroid plexus: target for systemic disease and pathway to the brain. Editorial. Lab. Invest. 56:231-233.

17. Scheld, W. M., T.-S. Park, R. G. Dacey, H. R. Winn, J. A. Jane, and M. A. J. Sande. 1979. Clearance of bacteria from cerebrospinal fluid to blood in experimental meningitis. Infect. Immun. 24:102-105.

18. Glode, M. P., A. Sutton, E. R. Moxon, and J. B. Robbins. 1977. Pathogenesis of neonatal Escherichia coli meningitis: induction of bacteremia and meningitis in infant rats fed $E$. coli $\mathrm{K} 1$. Infect. Immun. 16:75-80.

19. Finne, J. 1982. Occurrence of unique polysialosyl carbohydrate units in glycoproteins of developing brain. J. Biol. Chem. 257:1196611970.

20. DeVoe, I. W., and J. E. Gilchrist. 1975. Pili on meningococci from primary cultures of nasopharyngeal carriers and cerebrospinal fluid of patients with acute disease. J. Exp. Med. 141:297-305.

21. Stephens, D. S., K. M. Edwards, F. Morris, and Z. A. McGee. 1982. Pili and outer membrane appendages on Neisseria meningitidis in the cerebrospinal fluid of an infant. J. Infect. Dis. 146:568-569. 